\title{
Minimal-invasives Verfahren setzt schlaffes Lungengewebe unter Spannung
}

Interventionelle Verfahren gewinnen in der Therapie von Patienten mit fortgeschrittenem Lungenemphysem zunehmend an Bedeutung. Durch endoskopische Implantation von Spiralen ${ }^{1}$ aus Nitinol in den oberen bzw. unteren Lungenlappen kann bei ausgewählten Emphysem-Patienten die Lungenfunktion bei einem akzeptablen Sicherheitsprofil des Eingriffs deutlich verbessert werden.

Bei Emphysem-Patienten ist das Lungenparenchym so „weich“, dass es beim Ausatmen zum Bronchialkollaps und zum sog. Air Trapping kommt. Die Patienten können die Luft nur zum geringen Teil ausatmen, die Lunge ist stark überbläht. Nach Implantation der Spiralen wird das Lungenvolumen durch Kompression der am stärksten beeinträchtigten Bereiche des Lungenparenchyms reduziert und das Gewebe unter Spannung gesetzt. Das verbessert die elastische Rückstellkraft der Lunge, erleichtert die Ausatmung durch bessere Durchgängigkeit der Atemwege, berichtete Prof. Hans Klose, Hamburg, auf einem Industriesymposium im Rahmen des DGP-Kongresses ${ }^{2}$.

Üblicherweise werden bei einem Eingriff 10-14 Spiralen in gestreckter Form mittels Katheter in den betroffenen oberen bzw. unteren Lungenlappen eingesetzt die besten Ergebnisse erzielt man durch eine beidseitige Anwendung - nach der Freisetzung nehmen diese wieder ihre ursprüngliche Spiralform an. Zudem wird durch die Spiralen auch das Zwerchfell wieder in eine für die Atmung bessere Position gebracht, sagte Klose.

Die günstigen Effekte der Spiralen zeigten sich in klinischen Studien sowohl bei Patienten mit heterogenem als auch bei homogenem Emphysem. In einer europäischen Multicenterstudie wurden 60 Emphysem-Patienten behandelt, davon 55 bilateral ${ }^{3}$. Nach 6 Monaten zeigten $48 \%$ der Patienten eine mind. $12 \%$ ige Verbesserung der Einsekundenkapazität $\left(\mathrm{FEV}_{1}\right)$, nach 12 Monaten 41\%. Bei 65 bzw. 58\% der Behan- delten wurde eine Verringerung des Residualvolumens um mind. 0,351 beobachtet. Bei mehr als der Hälfte der Studienteilnehmer nahm die 6-Minuten-Gehstrecke um mind. 26 Meter zu. Die verbesserte körperliche Verfassung ging mit einer deutlichen Steigerung der Lebensqualität einher, gemessen mit dem St. George's Respiratory Questionnaire (SGRQ): Nach 6 Monaten berichteten $61 \%$ der Studienteilnehmer über eine Steigerung von mind. 8 Punkten, nach 12 Monaten $53 \%$. Bei der inhalativen Therapie werden i.d.R. nur Verbesserungen um 2-3 Punkte im Rahmen eines MCID (minimal clinically important difference)-Modells erreicht, so Klose.

\section{Nach einer Pressemitteilung \\ (PneumRx)}

\footnotetext{
${ }^{1}$ PneumRx ${ }^{\circledR}$ Endobronchial Coils, PneumRx GmbH, Düsseldorf

${ }^{2}$ Industriesymposium „Wege entstehen dadurch, dass man sie geht - Coils zur interventionellen Lungenemphysemtherapie“ und Meet the Experts „Lungenemphysem in Deutschland - Neue Wege in der Therapie“, im Rahmen der 56. Jahrestagung der Deutschen Gesellschaft für Pneumologie, Berlin, März 2015, Veranstalter: Pneum$\mathrm{Rx}$

${ }^{3}$ Deslee G et al. Thorax 2014; 69: 980 - 986
}

der Goldstandard beim ALK-positiven NSCLC.

Die Leitgruppe thorakale Tumore der Arbeitsgruppe Thorakale Onkologie in der AIO (Arbeitskreis internistische Onkologie in der Deutschen Krebsgesellschaft) empfiehlt bei Patienten mit einem Nicht-Plattenepithelkarzinom im Stadium IV und negativer EGFR (Epidermal Growth Factor Receptor) -Mutationsanalyse eine ALKDiagnostik. Die Analysen erfolgen bei der primären Diagnostik am Tumorgewebe. Für Patienten mit einem Plattenepithelkarzinom und Nichtraucherstatus bzw. früherem Nikotinabusus von weniger als 10 Packungsjahren seit mindestens 15 Jahren wird das gleiche Vorgehen empfohlen.

\section{Dr. Ralph Hausmann, Frankfurt}

\footnotetext{
1 Satellitensymposium: „ALK-positives NSCLC: Entdecken Sie jeden Patienten “, Mai 2015, Frankfurt, Veranstalter: Pfizer Oncology

${ }^{2}$ Shaw AT et al. NEJM 2013; 368: 2385-2394

${ }^{3}$ Xalkori ${ }^{\circledR}$, Pfizer Pharma GmbH, Berlin
} 